\title{
Different carbon isotope fractionation patterns during the development of phototrophic freshwater and marine biofilms
}

\author{
M. Staal ${ }^{1,{ }^{*}}$, R. Thar ${ }^{2}$, M. Kühl ${ }^{2}$, M. C. M. van Loosdrecht ${ }^{3}$, G. Wolf ${ }^{3}$, J. F. C. de Brouwer ${ }^{1}$, and J. W. Rijstenbil ${ }^{1,{ }^{* *}}$ \\ ${ }^{1}$ Department of Marine Microbiology, Netherlands Institute of Ecology - KNAW, P.O. Box 140, 4400 AC Yerseke, The \\ Netherlands \\ ${ }^{2}$ Marine Biological Laboratory, Institute of Biology, University of Copenhagen, Strandpromenaden 5, 3000 Helsingør, \\ Denmark \\ ${ }^{3}$ Department of Environmental Biotechnology, TU Delft, Julianalaan 67, 2628 BC Delft, The Netherlands \\ * present address: Marine Biological Laboratory, Institute of Biology, University of Copenhagen, Strandpromenaden 5, 3000 \\ Helsingør, Denmark \\ ** present address: AE3 Consultancy, Fuchsialaan 8, 4401HV Yerseke, The Netherlands
}

Received: 8 January 2007 - Published in Biogeosciences Discuss.: 24 January 2007

Revised: 11 June 2007 - Accepted: 2 August 2007 - Published: 8 August 2007

\begin{abstract}
Natural phototrophic biofilms are influenced by a broad array of abiotic and biotic factors and vary over temporal and spatial scales. Different developmental stages can be distinguished and growth rates will vary due to the thickening of the biofilm, which is expected to lead to a limitation of light or mass transport. This study shows that variation in $\mathrm{CO}_{2(\mathrm{aq})}$ availability leads to a fractionation shift and thereby affects $\delta^{13} \mathrm{C}$ signatures during biofilm development. For phototrophic freshwater biofilms it was found that the $\delta^{13} \mathrm{C}$ value became less negative with the thickening of the biofilm, while the opposite trend was found in marine biofilms. Modeling and $\mathrm{pH}$ profiling indicated that the trend in the freshwater system was caused by an increase in $\mathrm{CO}_{2(\mathrm{aq})}$ limitation resulting in an increase of $\mathrm{HCO}_{3}^{-}$as $\mathrm{C}$-source. The opposite trend in the marine system could be explained by a higher heterotrophic biomass and activity causing a higher carbon recycling and thereby lower $\delta^{13} \mathrm{C}$ values. We conclude that $\delta^{13} \mathrm{C}$ was more related to the net areal photosynthesis rate and carbon recycling, rather than to the growth rate of the biofilms.
\end{abstract}

\section{Introduction}

Phototrophic biofilms are surface-associated microbial communities, in which light is the ultimate source of energy and biomass originates mainly from microalgae and bacteria. They thrive on submerged biotic or abiotic substrata in lightexposed aquatic environments and exo-biopolymers (mostly polysaccharides) provide adhesion and cohesion to the microbial consortia in these biofilms (Decho, 2000). During the initial phase of biofilm development the maximum growth rate is determined by the incident irradiance, since at that stage the biofilm thickness does not limit diffusive transport of any of the substrates. Eventually, with the thickening of a biofilm both light attenuation and diffusive transport will progressively become limiting factors for growth. Diffusion limitation will increase during the development of a biofilm due to an increased biovolume-to-surface ratio, while the potential volumetric enzymatic rates remain equal. At high irradiances mass transfer eventually determines the maximum thickness of a biofilm.

Phototrophic biofilms grow in all aquatic systems ranging from freshwater to hyper saline and all oxygenic phototrophs use RUBISCO in their photosynthetic apparatus for carbon fixation, and the inorganic carbon source used by RUBISCO is $\mathrm{CO}_{2(\mathrm{aq})}$. One difference between freshwater and seawater chemistry is that seawater has higher inorganic carbon contents and stronger carbonate buffering (Stumm and Morgan, 1995). This results in a higher $\mathrm{pH}$ and a dominance in bicarbonate concentration relative to $\mathrm{CO}_{2(\mathrm{aq})}$. In marine systems the dissolved inorganic pool consists of dissolved $\mathrm{CO}_{2}$ $(<1 \%), \mathrm{HCO}_{3}^{-}(\sim 95 \%)$, and $\mathrm{CO}_{3}^{2-}(\sim 5 \%)$. Due to the low $\mathrm{CO}_{2 \text { (aq) }}$ concentration and a slow chemical conversion rate of $\mathrm{HCO}_{3}^{-}$to $\mathrm{CO}_{2}$, the supply of $\mathrm{CO}_{2(\mathrm{aq})}$ may be considered as a potentially limiting factor. On the other hand, high respiration rates of heterotrophic and phototrophic organisms present in biofilms may elevate the $\mathrm{CO}_{2 \text { (aq) }}$ levels and as a result lower the $\mathrm{pH}$.

Correspondence to: M. Staal

(mstaal@bi.ku.dk)

Published by Copernicus Publications on behalf of the European Geosciences Union. 
The inorganic carbon pool available for phototrophs consists of carbon atoms with different atomic weights, mainly ${ }^{12} \mathrm{C}(\sim 99 \%)$ and ${ }^{13} \mathrm{C}(\sim 1 \%)$ (Raven, 1998). Organic carbon in phototrophic organisms is generally depleted in ${ }^{13} \mathrm{C}$ relative to the carbon source. This depletion is caused by a biological fractionation due to an enzymatic discrimination against ${ }^{13} \mathrm{C}$ in the photosynthetic process (Hayes, 1993). Under non-limiting conditions, fractionation by RUBISCO results in a $\delta^{13} \mathrm{C}$ ranging from $-29 \%$ in plants to $-21 \%$ in cyanobacteria (Roeske and O'Leary, 1985); eukaryotic algae have $\delta^{13} \mathrm{C}$ values intermediate of these (Lewis et al., 2000). However, the overall fractionation of $\delta^{13} \mathrm{C}$ in phototrophic biofilms is not only the result of the biochemical properties of RUBISCO, but is also affected by $\mathrm{CO}_{2 \text { (aq) }}$ limitation within the biofilm, which will lower the effective enzymatic fractionation of RUBISCO for two reasons: First, the competition between both substrates ${ }^{13} \mathrm{CO}_{2(\mathrm{aq})}$ and ${ }^{12} \mathrm{CO}_{2(\mathrm{aq})}$ for the binding sites in RUBISCO becomes less as the diffusive transport becomes more important for the $\mathrm{CO}_{2}$ binding rate to the enzyme; it can be assumed that the diffusive transport rate is equal for both substrates. Second, discrimination against ${ }^{13} \mathrm{C}$ will lead to a ${ }^{13} \mathrm{C}$ enrichment of the remaining

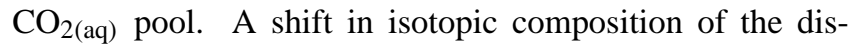
solved inorganic carbon (DIC) pool will result in an additional change in $\delta^{13} \mathrm{C}$ of the organic matter since fractionation $(\varepsilon)$ is independent of the $\delta^{13} \mathrm{C}$ from the source (Lewis et al., 2000; Werne and Hollander, 2004; Hayes, 1993).

Many algae can increase the conversion rate of $\mathrm{HCO}_{3}^{-}$to $\mathrm{CO}_{2 \text { (aq) }}$ by the enzyme carbonic anhydrase (CA) (Tortell and Morel, 2002; Cassar et al., 2004) and thereby increase the availability of $\mathrm{CO}_{2}$ for RUBISCO. This enzyme catalyzes the hydration and dehydration of $\mathrm{CO}_{2}$. The presence of CA activity in phototrophic biofilms will influence the $\delta^{13} \mathrm{CO}_{2(\mathrm{aq})}$ and can increase the biomass $\delta^{13} \mathrm{C}$ up to $10 \%$ o (Goericke et al., 1994).

Most studies on $\delta^{13} \mathrm{C}$ in photosynthetic microorganisms focus on phytoplankton species and it is found that $\delta^{13} \mathrm{C}$ values of cultured marine phytoplankton species vary from $-30 \%$ to $-18 \%$, while freshwater phytoplankton $\delta^{13} \mathrm{C}$ ranges between $-40 \%$ o to $-25 \%$ o. The $\delta^{13} \mathrm{C}$ values do not only vary amongst species (Lewis et al., 2000), they also vary within species due to environmental factors such as growth rate, $\mathrm{pH}$ of the medium (i.e. $\mathrm{CO}_{2(\mathrm{aq})}$ availability) and irradiance (Johnston et al., 2004; Swansburg et al., 2002). $\delta^{13} \mathrm{C}$ values are frequently used as proxies for food sources in food web studies (delGiorgio and France, 1996; March and Pringle, 2003). Since phototrophic biofilms can be important food sources in aquatic ecosystems (Bott, 1996; Charlebois and Lamberti, 1996; France, 1996; Boschker et al., 2005) it is important to understand the processes that cause variations in $\delta^{13} \mathrm{C}$ within such surface-associated communities. Little is known about the factors that influence the $\delta^{13} \mathrm{C}$ of phototrophic biofilms but the values are reported to vary with growth rate, irradiance, turbulence, and flow velocity (Trudeau and Rasmussen, 2003; France, 1995a).
In this study we investigated the development of marine and freshwater phototrophic biofilms grown under defined environmental conditions from natural inoculates. We measured the $\delta^{13} \mathrm{C}$ values at the different stages in the biofilm development along with a range of water chemistry and biofilm parameters. The aim of the study was to analyze the variation of the $\delta^{13} \mathrm{C}$ during biofilm development and identify key biotic and abiotic processes for carbon isotope fractionation in phototrophic biofilms.

\section{Methods}

Freshwater and marine phototrophic biofilms were grown on removable transparent polycarbonate slides in an incubator (Zippel and Neu, 2005), allowing the development of algaldominated biofilms at defined irradiance and flow regimes. The incubator contains 4 physically separated incubation lanes, each with a specific irradiance. Every lane had its own growth medium reservoir. Incubators were inoculated with homogenized phototrophic biofilm material. The inoculum for the freshwater biofilms grew on surfaces in the sedimentation tank of the waste water treatment of Fumicino airport, Rome (Congestri et al., 2005). The marine inoculum originated from biofilms growing on continuously submerged surfaces in flowing Oosterschelde water, the Netherlands. Inoculation material was mechanically homogenized and then frozen in order to kill fauna and prevent top-down control of the biofilm as much as possible. The freshwater medium was a modified BG 11-medium (http://www.pasteur.fr/recherche/ banques/PCC/Media.htm), with $20 \mu \mathrm{M}$ silicate to allow diatom development. The marine biofilms were grown in medium prepared with commercially available aquarium sea salt (HW Meeressalz Professional, Wiegand, Germany) with additional silicate $(20 \mu \mathrm{M})$, nitrate $(0.35 \mathrm{mM})$, and phosphate $(24 \mu \mathrm{M})$.

The medium $(4 \mathrm{~L}$ per lane) was continuously circulated at flow rates of 25 or $100 \mathrm{l} / \mathrm{h}$ and was replaced twice a week. The water level was $\sim 3 \mathrm{~mm}$ above the biofilm, resulting in a water velocity of $\sim 0.5$ or $2 \mathrm{~m} / \mathrm{s}$. The $\mathrm{pH}$ of the medium was measured with a $\mathrm{pH}$ electrode after its preparation. The $\mathrm{pH}$ of renewed freshwater medium was 7.7 while it was 8.1 for the marine medium. It was found that the $\mathrm{pH}$ changed during the residence period of 3 or 4 days of the medium in the incubator. Biofilms were grown at a range of different growth conditions (Table 1) and the development of the biofilm was followed by continuous recording of the light absorbance using 9 light sensors glued on the bottom of several slides along each flow lane. Absorbed light absorbance was used as a proxy for the phototrophic biomass at the given growth conditions (Zippel et al., 2007). Growth rates were estimated by fitting a Richards logistic growth equation (Sidorkewicj et al., 1999) through the light absorption values. The fit quality of the logistic growth model through the measuring points was high (average $r^{2}=0.975 \pm 0.038$, lowest $r^{2}$ value was 0.820 ). 
Table 1. Growth conditions and relative growth rates at the different incubations. Relative growth rates were calculated at a biomass $50 \%$ light absorption using the fitted parameters from the logistic growth equation. The fit quality of the growth model trough the measuring points was high (average $\mathrm{r}^{2}=0.975 \pm 0.038$ ).

\begin{tabular}{|c|c|c|c|c|c|c|}
\hline \multirow[t]{3}{*}{ medium } & \multirow[t]{3}{*}{ temperature } & \multirow[t]{3}{*}{ Flow $\mathrm{m} / \mathrm{s}$} & \multicolumn{4}{|c|}{$\begin{array}{c}\text { Relative Growth rate at } \\
50 \% \text { absorbance }\end{array}$} \\
\hline & & & \multicolumn{4}{|c|}{ Irradiance } \\
\hline & & & 15 & 30 & 60 & 120 \\
\hline \multirow[t]{4}{*}{ freshwater } & 20 & 0.5 & 0.54 & 1.55 & 1.56 & 1.78 \\
\hline & & 2 & 0.65 & 0.86 & 1.14 & 2.11 \\
\hline & 30 & 0.5 & 0.34 & 0.52 & 1.08 & 1.44 \\
\hline & & 2 & 0.66 & 1.18 & 2.40 & 3.31 \\
\hline \multirow[t]{4}{*}{ salt water } & 25 & 0.5 & 0.83 & 1.24 & 2.41 & 2.72 \\
\hline & & 2 & 0.74 & 0.86 & 1.46 & 2.01 \\
\hline & 15 & 0.5 & 0.53 & 0.84 & 1.13 & 1.97 \\
\hline & & 2 & 0.74 & 0.79 & 1.61 & 1.89 \\
\hline
\end{tabular}

For sampling the biofilm samples were scraped off the slide and the wet weight was determined for each sample. The samples dry weight was measured and samples were stored at $-80^{\circ} \mathrm{C}$ until $\delta^{13} \mathrm{C}$ analysis. The wet weight of the biofilms was found to increase linearly with light absorption values of up to $85-90 \%$ (data not shown). The $r^{2}$ was $0.38 \quad(n=34)$ and $0.55(n=44)$ for the pooled freshwater and marine incubations respectively (both regression lines were significant; $P<0.01)$.

The $\delta^{13} \mathrm{C}$ values were determined at 3 different growth stages during biofilm development. A first sample was always taken 10 days after inoculation (initial phase), the second sample was taken at the first working day after $\sim 50 \%$ light absorption was reached (exponential growth phase) and the third sample was taken at the first working day after $\sim 90 \%$ light absorption was reached (mature or stationary phase). Sampling started close to the outlet of the incubator to prevent disturbance of biofilms growing on the other slides. Sampled slides were replaced by slides with no biofilm to prevent additional turbulence caused by height differences. There were not enough slides in the incubator for (pseudo) replicate sampling per irradiance per growth stage. However, a test run on freshwater medium revealed $\delta^{13} \mathrm{C}$ values of $-23.33 \pm 0.48,-24.55 \pm 0.33,-27.66 \pm 1.07$ and $35.17 \pm 0.02$ for the lanes with irradiances of 120, 60, 30 and $15 \mu \mathrm{mol}$ photons $\mathrm{m}^{-2} \mathrm{~s}^{-1}$ respectively. Standard deviations of the average values $(n=3)$ were low $(\mathrm{SD}<4 \%$ of average value) and therefore a randomly sampled slide may be considered as representative for the entire lane.

\subsection{Stable isotope analysis}

Biofilm samples were analyzed for natural $\delta^{13} \mathrm{C}$ abundance by a total combustion elemental analyzer coupled to an isotope ratio mass spectrometer (IRMS) (Finnigan, Germany).
Samples were combusted at $1010^{\circ} \mathrm{C}$ and transported with a helium (5.0 purity) carrier gas flow to the IRMS for determining the isotopic ${ }^{13} \mathrm{C} /{ }^{12} \mathrm{C}$ ratio of carbon. Stable isotope ratios were calculated as:

$\delta^{13} \mathrm{C}=\left(\frac{\left(\frac{{ }^{13} \mathrm{C}}{{ }^{12} \mathrm{C}}\right)_{\text {sample }}}{\left(\frac{{ }^{13} \mathrm{C}}{{ }^{12} \mathrm{C}}\right)_{\text {standard }}}-1\right) \times 1000$

where the standard is the $\mathrm{C}$-isotope ratio of Vienna PeeDee Belemnite (0.0112372).

Samples for total dissolved inorganic carbon (DIC) were taken weekly per lane as well as of new made medium. The concentration of DIC in the medium was determined by acidifying $50 \mathrm{ml}$ medium with $500 \mu \mathrm{l}$ pure phosphoric acid in a closed container (Crimp Seal, Chrompack, the Netherlands) to convert all $\mathrm{HCO}_{3}^{-}$and $\mathrm{CO}_{3}^{2-}$ into $\mathrm{CO}_{2}$. The samples were stored at room temperature to reach equilibrium with the gas phase $(5 \mathrm{ml}) .500 \mu \mathrm{l}$ of the gas phase was injected into a GC with a Poraplot Q column which was linked to the IRMS (Finnigan, Germany) for $\delta^{13} \mathrm{C}$ analysis. The $\mathrm{CO}_{2(\mathrm{aq})}$ concentration was calculated using a calibration curve.

Fractionation $(\varepsilon)$ was calculated for each growth phase as the difference between the average $\delta^{13} \mathrm{DIC}$ and the $\delta^{13} \mathrm{C}$ of the biofilm sampled at that phase. Fractionation was calculated according to the equation:

$\varepsilon=\left(\delta^{13} \mathrm{DIC}-\delta^{13} \mathrm{C}_{\text {biofilm }}\right) /\left(1+\delta^{13} \mathrm{C}_{\text {biofilm }} / 1000\right)$

(Freeman and Hayes, 1992). Fractionation was calculated directly for the initial phase biofilms. However, during the exponential and mature phase, fractionation was calculated from the average $\delta^{13}$ DIC during each specific development stage and the $\delta^{13} \mathrm{C}$ of the newly formed biomass. The $\delta^{13} \mathrm{C}$ of the newly formed biomass was calculated according to

$\frac{b_{t+1} \delta^{13} \mathrm{C}_{t+1}-b_{t} \delta^{13} \mathrm{C}_{t}}{\left(b_{t+1}-b_{t}\right)}$ 
where $b_{t+1}$ denotes the C-biomass at the phase of sampling and $b_{t}$ the C-Biomass in the previous phase.

\subsection{PLFA-determination}

Phospholipid-derived fatty acids (PLFA) originating from cell membranes were used as group specific biomarkers to determine the relative abundance of heterotrophic and phototrophic biomass. PLFA extraction and derivatization was done by an adapted Blyer and Digh protocol (Boschker, 2004). Analysis of the methylated forms of PLFA was done by gas chromatography-flame ionization detection (GC-FID, Interscience, Belgium) using a polar analytical column (Scientific Glass Engineering BPX-70). Biomass contribution of heterotrophic components was estimated by Chemtax as described in Dijkman et al. (2006)

\section{$2.3 \mathrm{pH}$ profiling}

Three adjacent slides covered with biofilm were removed from the incubator and positioned into an external flow chamber with fresh medium. The environmental conditions in the external flow chamber (flow, temperature, irradiance) were identical to the respective conditions in the biofilm incubator. Glass pH microelectrodes (Glud et al., 1992) were used to measure depth-profiles of $\mathrm{pH}$ in the phototrophic biofilms. The $\mathrm{pH}$ microelectrode and a standard calomel reference electrode (Radiometer, Denmark) were connected to a high-impedance millivoltmeter (Keithley, USA). The microsensor was mounted on a motorized micromanipulator (Unisense A/S, Denmark) and depth-profiles were automatically recorded on a PC with a data acquisition system (Profix, Unisense A/S, Denmark). The $\mathrm{pH}$ microsensors were calibrated in standard $\mathrm{pH}$ buffer solutions of $\mathrm{pH} 7$ and $\mathrm{pH} 10$ (Radiometer, Denmark) and exhibited almost ideal Nernstian response characteristics and a response time of $<60 \mathrm{~s}$. The surface position where the $\mathrm{pH}$ microsensor touched the biofilm surface was estimated by visual inspection with a dissection microscope while approaching the sensor tip to the biofilm surface. In order to ensure steady state conditions, the biofilm samples were left in the external flow chamber for $30 \mathrm{~min}$ in the light before $\mathrm{pH}$ measurements were initiated. Similarly, light was switched off for $30 \mathrm{~min}$ before the $\mathrm{pH}$ profiles in darkness were acquired.

\subsection{Biofilm modeling}

In order to explain the variation in $\delta^{13} \mathrm{C}$ values found in the freshwater biofilms, we constructed a model describing the chemical and biological processes in a developing freshwater biofilm. Growth and relevant metabolic and geochemical processes in the biofilm were modeled with the $\mathrm{PHO}$ $B I A$ biofilm kinetic model programmed in Aquasim 2.1 (details in Wolf et al., 2007). The model is a multi-species and multi-substrate mechanistic biofilm model, which has been developed based on the general one-dimensional mathematical biofilm model (Reichert, 1998). It contains kinetics that describes the interactions between photoautotrophic, heterotrophic and chemoautotrophic (nitrifying) functional microbial groups. The biological processes in the model include biomass growth, biomass inactivation and lysis, substrate and nutrient conversion. Growth is estimated as maximum growth rate multiplied by a limitation term, based on the most limiting substrate at the given time points. Light is considered as an energy source and light dependent carbon fixation by phototrophs is modeled via the Eilers and Peeters relationship (Eilers and Peters, 1988), which accounts for light saturation and photoinhibition. Biofilm-specific phenomena are taken into account, such as extracellular polymeric substances (EPS) production by phototrophs as well as gradients of substrates and light in the biofilm. Acidbase equilibria, in particular carbon speciation, are explicitly accounted for, allowing for the calculation of $\mathrm{pH}$ profiles and profiles of the different abiotic carbon species across the biofilm based on chemical acid-base-equilibriums as well as consumption and production terms. The model distinguishes between the usage of different inorganic carbon sources by photoautotrophs, i.e. $\mathrm{CO}_{2(\mathrm{aq})}$ and bicarbonate and combines a number of kinetic mechanisms specific to phototrophic microbial communities, such as internal polyglucose storage under dynamic light conditions, phototrophic growth in the darkness using internally stored reserves, photoadaptation and photoinhibition. We used the same model parameters as Wolf et al. (2007). The settings of the model were based on the measured DIC concentrations and biofilm photosynthesis/respiration rates within the incubator (data not shown).

\subsection{Statistical considerations}

Due to some lacking data points and the impossibility of replication it was impossible to use multiple component statistical analysis tests. Therefore, the results have been tested per parameter using the single factor ANOVA test. If variation of an incubation parameter (i.e. flow rate, temperature, irradiance, medium type) did not yield significant differences in the measured growth parameters, we considered it acceptable to pool data of that specific parameter for further analysis.

\section{Results}

Phototrophic biofilm development depended mainly on irradiance (Fig. 1). High incident irradiance resulted in a shorter lag time as well as in a faster biofilm development due to a higher growth rate. Relative growth rates at 50\% light absorption, as calculated from the fitted logistic growth curve (Table 1), varied significantly with irradiance $(P<0.05)$ within the growth conditions applied. We found no differences in the relative growth rates (at 50\% 
light absorption) between marine or freshwater biofilms, nor did we find an effect of the flow rate on the growth rate $(P>0.05)$. The temperature seemed to have some effect on the growth rate, but within the experimental design this was not significant $(P>0.05)$.

The $\delta^{13} \mathrm{C}$ values of the different biofilms were measured at three developmental stages. For the freshwater biofilms it was found that $\delta^{13} \mathrm{C}$ values became less negative with an increase in biomass (Figs. 2a-d, similar trends in $\delta^{13} \mathrm{C}$ values were also found in biofilms grown outdoors in a helophyte filter, see Fig. 1 in supplementary information - http://www.biogeosciences.net/4/613/ 2007/bg-4-613-2007-supplement.pdf). Changes in $\delta^{13} \mathrm{C}$ were strongest for biofilms grown at the highest irradiances. However, the increase was not related to the actual growth rate of the biofilm. The biofilm development was described well by a logistic growth model. A logistic growth model per definition depicts a decrease in net growth rate as soon as biomass values reach a value above $50 \%$ of the maximum biomass in the system. Considering the good fit quality of the model through the measured growth curves (average $r^{2}=0.975 \pm 0.038 n=24$ curves, lowest $r^{2}$ value was 0.820 ), it implies that the actual growth rate was highest during the initial and exponential phase, whereas the net growth rate decreased thereafter with biofilm thickening (see also Fig. 2 in supplementary information - http://www.biogeosciences.net/4/613/ 2007/bg-4-613-2007-supplement.pdf). At the point where the $\delta^{13} \mathrm{C}$ value increased, the average growth rate was below the maximum growth rate.

The $\delta^{13} \mathrm{C}$ values showed a contrasting trend during the development of the marine biofilm (Figs. $3 \mathrm{a}-\mathrm{d}$ ). The $\delta^{13} \mathrm{C}$ values during the initial phase were higher $(\sim 9 \%)$ than in the freshwater biofilms, but instead of increasing with the thickening of the biofilm, the values became more negative over time.

The DIC concentrations were $0.34 \pm 0.05 \mathrm{mM}$ and $1.5 \pm 0.4 \mathrm{mM}$ in the freshwater and marine medium, respectively. The $\delta^{13} \mathrm{DIC}$ in the media were measured for the two $30^{\circ} \mathrm{C}$ freshwater runs and for all marine runs. The average initial $\delta^{13}$ DIC value in freshwater was $-10.9 \pm 0.8 \%$ o while it was $-6.6 \pm 1.2 \%$ in salt water medium. For the incubations of which $\delta^{13}$ DIC values were measured it was possible to calculate the fractionation $(\varepsilon)$ for each growth phase (Fig. 4). The fractionation was significantly lower in the marine $(\varepsilon=13.1 \pm 1.5 \%, n=16)$ compared to the freshwater incubations $(\varepsilon=17.5 \pm 1.5 \%, n=8)(P<0.05)$ during growth in the initial phase. No effect of irradiance on fractionation was found during this phase for both marine and freshwater incubations ( $P_{\text {freshwater }}=0.267$ and $P_{\text {marine }}=0.42$ ). For the freshwater runs a trend of decreasing fractionation with increasing irradiances was found during the exponential growth phase. This trend was stronger during mature growth. Fractionation values did not differ significantly between the irradiances regime during growth
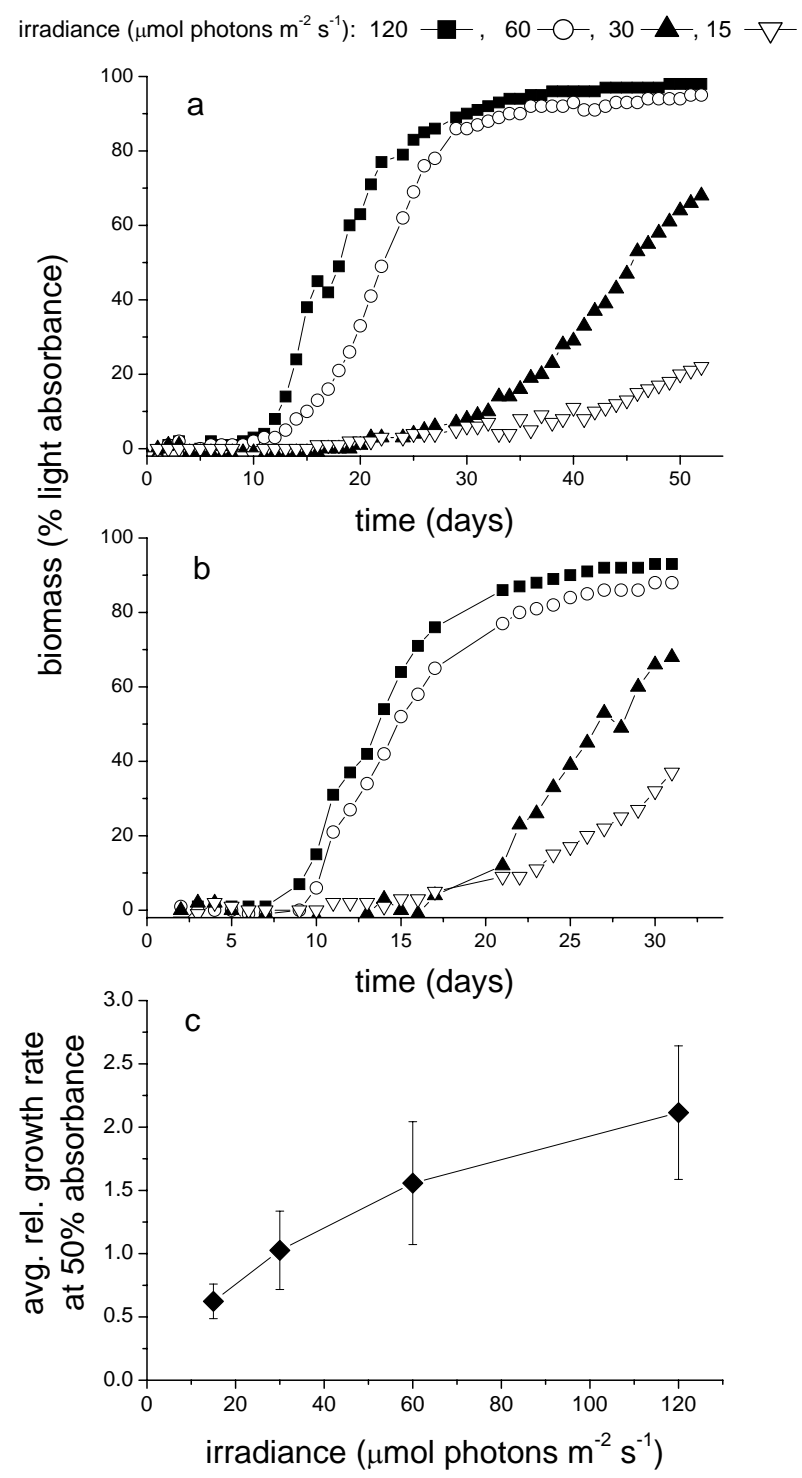

Fig. 1. Biomass development of phototrophic biofilms grown in freshwater and marine growth mediums. (a) Typical example of biomass development at 4 different irradiances in a freshwater growth medium, incubated at $30^{\circ} \mathrm{C}$ and $0.5 \mathrm{~m} / \mathrm{s}$ flow. (b) Typical example of biomass development at 4 different irradiances in a marine growth medium, incubated at $15^{\circ} \mathrm{C}$ and $0.5 \mathrm{~m} / \mathrm{s}$. (c) Average relative growth rates at $50 \%$ light absorbance for the four different irradiances. One overall average growth rate per irradiance was calculated from the growth rates of all incubations. The error bars represent the standard deviation on the average value. The relative growth rates were estimated using a logistic growth model.

in these phases $(P>0.05)$. The marine incubations showed an increase in fractionation at all irradiance regimes during the exponential phase. In the mature phase this increase continued at $60 \mu \mathrm{mol}$ photons $\mathrm{m}^{-2} \mathrm{~s}^{-1}$. An opposite trend was found for the incubations at $120 \mu$ mol photons $\mathrm{m}^{-2} \mathrm{~s}^{-1}$. At this irradiance fractionation decreased during the mature phase. Fractionation values differed significantly $(P<0.05)$ between both irradiances in mature marine biofilms. 

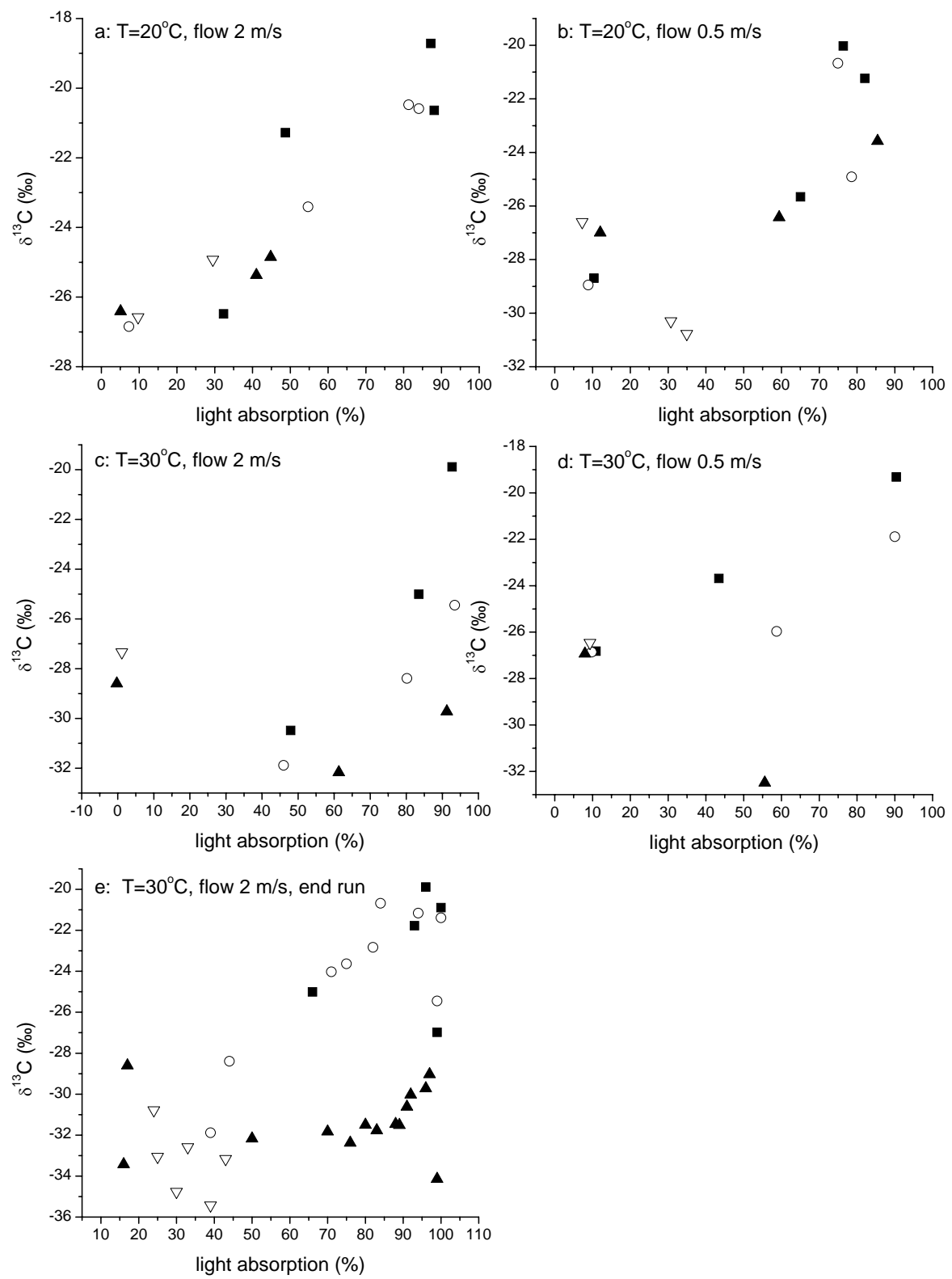

Fig. 2. Development of $\delta^{13} \mathrm{C}$ values in the bulk biomass in developing freshwater phototrophic biofilms. Figures (a-d) show the relationship of $\delta^{13} \mathrm{C}$ values with biomass for each treatment (temperature and flow rate are indicated in the graphs). Biomass is expressed as light absorption. (e) $\delta^{13} \mathrm{C}$ value samples taken at the end of the run to overcome the effects in changes in $\mathrm{pH}$ in the medium. Symbols indicate different irradiances $120 \mu \mathrm{mol}$ photons $\mathrm{m}^{-2} \mathrm{~s}^{-1}$ (closed squares), $60 \mu \mathrm{mol}$ photons $\mathrm{m}^{-2} \mathrm{~s}^{-1}$ (open circles), $30 \mu \mathrm{mol} \mathrm{photons}^{-2} \mathrm{~s}^{-1}$ (closed triangles) and $15 \mu \mathrm{mol}$ photons $\mathrm{m}^{-2} \mathrm{~s}^{-1}$ (open triangles).

For one freshwater run and one marine run, additional $\delta^{13} \mathrm{C}$ samples were taken at the end of the run. The reason for the additional sampling was that the $\mathrm{pH}$ in the medium changed during the incubation (Fig. 5) affecting the $\mathrm{CO}_{2(\mathrm{aq})} / \mathrm{HCO}_{3}^{-}$ratio in the overlying water, which may explain the observed variations in $\delta^{13} \mathrm{C}$. The change in $\mathrm{pH}$ was more pronounced at high biofilm biomass and high irradiance.
For this additional sampling, we used slides that were put in the incubator as a replacement of the slides sampled during the course of the run. Some of these slides (replacements for the mature samples) have only been for 5-8 days in the incubator and only contained little biomass (equivalent to the initial phase). The difference with the normal incubations is that these low biomass samples have been incubated, in medium at the moment that the $\mathrm{pH}$ change were most pronounced. Despite this difference in the $\mathrm{pH}$ history, 

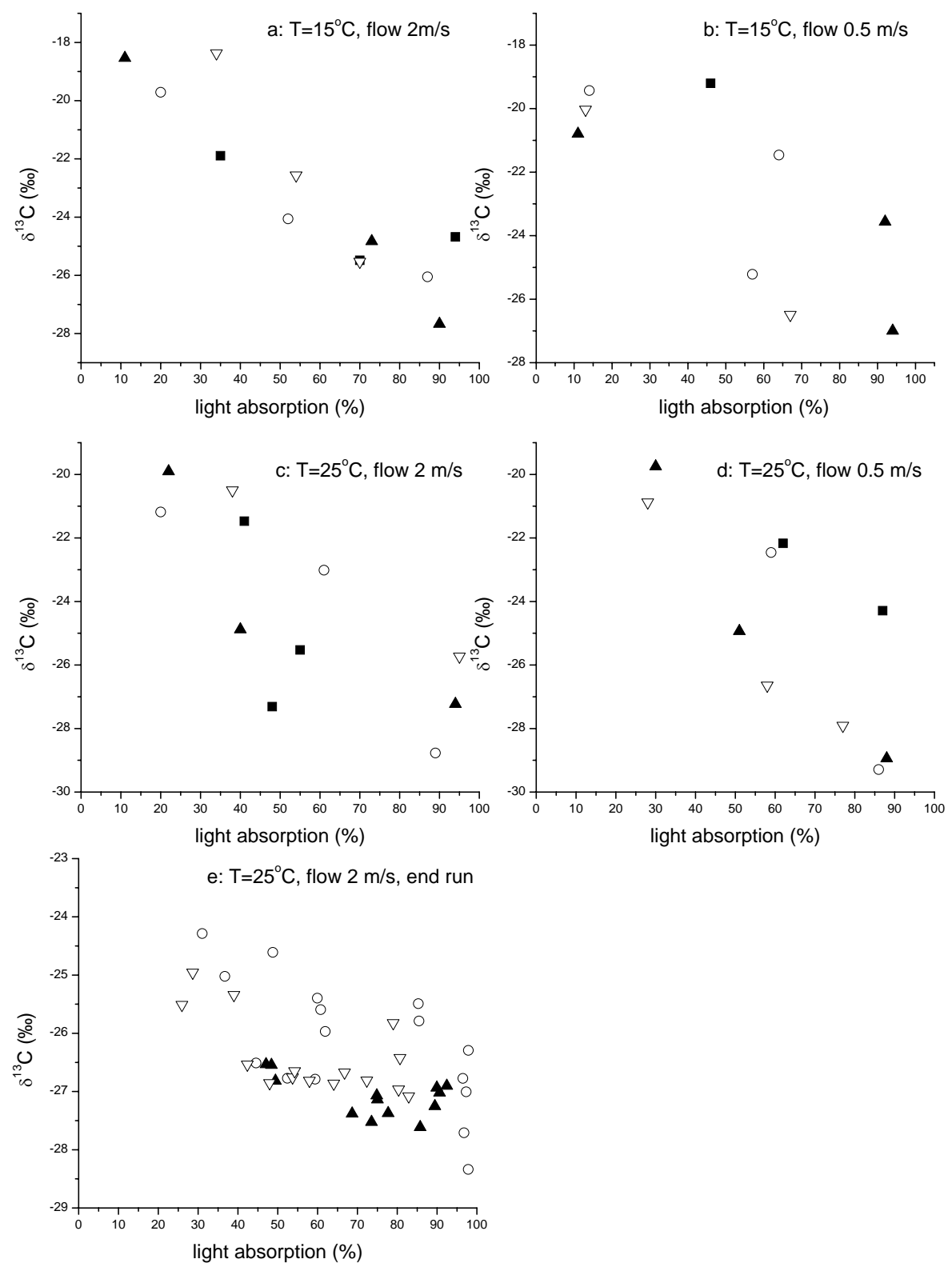

Fig. 3. Development of $\delta^{13} \mathrm{C}$ values in the bulk biomass in developing marine phototrophic biofilms. Figures (a-d) show the relationship of $\delta^{13} \mathrm{C}$ values with biomass per treatment (temperature and flow rate are indicated in the graphs). Biomass is expressed as light absorption. (e) $\delta^{13} \mathrm{C}$ value samples taken at the end of the run to overcome the effects in changes in $\mathrm{pH}$ in the medium. Symbols indicate different irradiances $120 \mu \mathrm{mol}$ photons $\mathrm{m}^{-2} \mathrm{~s}^{-1}$ (closed squares), $60 \mu \mathrm{mol}$ photons $\mathrm{m}^{-2} \mathrm{~s}^{-1}$ (open circles), $30 \mu \mathrm{mol}$ photons $\mathrm{m}^{-2} \mathrm{~s}^{-1}$ (closed triangles) and $15 \mu \mathrm{mol}$ photons $\mathrm{m}^{-2} \mathrm{~s}^{-1}$ (open triangles).

the $\delta^{13} \mathrm{C}$ values in these additional experiments showed the same trend with biomass development (Figs. 2e and 3e) as was found in the normal freshwater and marine experiments. However, the effect of light was more pronounced than observed under the normal sampling procedure. Unfortunately we were not able to collect samples from the marine $120 \mu \mathrm{mol}$ photons $\mathrm{m}^{-2} \mathrm{~s}^{-1}$ for this experiment, since growth on these replacement slides was so fast that they were all above the $85-90 \%$ absorption value for longer than one week.
Besides the $\mathrm{pH}$ of the medium, $\mathrm{pH}$ depth profiles were measured in biofilms, both in the exponential and the mature growth phase (Fig. 6). Biofilm thickness varied considerably at each growth stage. This is indicative for a large spatial heterogeneity of the biofilm structure but the profiles show a consistent and representative trend of typical in situ $\mathrm{pH}$ characteristics for each treatment. In darkness, the $\mathrm{pH}$ in the freshwater biofilm matrix did not vary significantly from the $\mathrm{pH}$ in the overlaying water, whereas in light the $\mathrm{pH}$ clearly increased with depth. This can be taken as an 
Table 2. Percentage of heterotrophic biomass relative to the total biomass present in the different treatments based on chemtax analysis of the PLFA determination (NA = not analyzed due to a low amounts of biomass).

\begin{tabular}{|c|c|c|c|c|c|c|}
\hline \multirow[t]{2}{*}{ Medium } & \multirow[t]{2}{*}{ Temperature } & \multirow[t]{2}{*}{ Flow $(\mathrm{m} / \mathrm{s})$} & \multicolumn{4}{|c|}{$\begin{array}{l}\text { Irradiance } \mu \text { mol photons } \\
\qquad \mathrm{m}^{-2} \mathrm{~s}^{-1}\end{array}$} \\
\hline & & & 120 & 60 & 30 & 15 \\
\hline \multirow[t]{4}{*}{ Freshwater } & 20 & 0.5 & 7 & 5 & 15 & 8 \\
\hline & & 2 & 2 & 8 & 15 & NA \\
\hline & 30 & 0.5 & 2 & 6 & 6 & NA \\
\hline & & 2 & 5 & 2 & 2 & NA \\
\hline Average Freshwater & & & 4 & 5 & 10 & 8 \\
\hline \multirow[t]{4}{*}{ Saltwater } & 15 & 0.5 & 6 & 11 & 11 & NA \\
\hline & & 2 & 18 & 15 & 17 & 19 \\
\hline & 25 & 0.5 & 15 & 23 & 19 & 58 \\
\hline & & 2 & 22 & 36 & 44 & NA \\
\hline Average marine & & & 15 & 21 & 23 & 39 \\
\hline
\end{tabular}

indication of a high $\mathrm{CO}_{2}$ consumption due to photosynthesis. The increase in $\mathrm{pH}$ with depth was most pronounced in the mature biofilms. In addition, a higher irradiance resulted in a more pronounced increase in $\mathrm{pH}$. In marine biofilms it was found that in the dark the $\mathrm{pH}$ in the biofilm decreased with depth. In the light an increase was found in the upper part of the biofilm, while at deeper parts the $\mathrm{pH}$ decreased again and/or remained stable. A decrease in $\mathrm{pH}$ can be caused by a net production of $\mathrm{CO}_{2}$ resulting from high respiratory activity. The increase in $\mathrm{pH}$ in the upper part of the biofilm was linked to photosynthetic activity and was strongest at high irradiance.

PLFA analyses showed that the heterotrophic bacterial biomass was always highest in the marine runs. The average contribution of bacteria in the marine biofilms was almost twice the value of the freshwater biofilms (Table 2).

3.1 Modeled differences in $\mathrm{CO}_{2}$ consumption vs. $\mathrm{HCO}_{3}^{-}$ consumption

The model describes the $\mathrm{pH}$ in the biofilm based on charge balance, including the speciation of the different forms of inorganic carbon due to transport, chemical and biological conversion processes. The speciation of the different inorganic $\mathrm{C}$ pools was calculated with the model for a freshwater biofilm of $500 \mu \mathrm{m}$ thickness (Fig. 7a). It was found that at an irradiance of $120 \mu \mathrm{mol}$ photons $\mathrm{m}^{-2} \mathrm{~s}^{-1}$, most of the $\mathrm{CO}_{2}$ was consumed in the upper $150 \mu \mathrm{m}$ of the biofilm. The $\mathrm{HCO}_{3}$-pool was much larger than the $\mathrm{CO}_{2(\mathrm{aq})}$ pool and its concentration decreased relatively less with depth. Within the model, $\mathrm{CO}_{2}$ is preferred above $\mathrm{HCO}_{3}^{-}$as carbon source and therefore the $\mathrm{CO}_{2}$ consumption rate was highest in the top layer, while in that region almost no $\mathrm{HCO}_{3}^{-}$was consumed (Fig. 7b). The significance of $\mathrm{HCO}_{3}^{-}$as $\mathrm{C}$-source in- creased with depth and maximal $\mathrm{HCO}_{3}^{-}$consumption was found at $350 \mu \mathrm{m}$ depth. Below this depth, irradiance became limiting and determined the photosynthesis rate rather than the availability of the different inorganic C-pools. With the same model, an estimate of the depth integrated consumption rate of the different inorganic carbon pools during the biomass development was calculated (Figs. 8a and b). It was found that initially $\mathrm{CO}_{2}$ was the most important $\mathrm{C}$ - source for carbon fixation. With increasing biofilm thickness of the the relevance of $\mathrm{CO}_{2}$ for photosynthesis decreased. For thick biofilms $(>400 \mu \mathrm{m}), \mathrm{HCO}_{3}^{-}$eventually became the most important $\mathrm{C}$-source for photosynthesis (Fig. 8b).

\section{Discussion}

We will start the discussion with the freshwater system, where we observed that $\delta^{13} \mathrm{C}$ values increased with the development of phototrophic biofilms. In the initial growth phase no clear correlation was found between $\delta^{13} \mathrm{C}$ values and the growth rate or irradiance, indicating that the biofilm growth rate did not affect isotopic fractionation rates at this stage. This is in contrast with relationships found for isotope fractionation in phytoplankton, where several studies showed that the growth rate (Fry and Wainright, 1991; Laws et al., 1995; Rau et al., 1996) and irradiance (Rost et al., 2002) had an inverse relationship with isotopic fractionation in different phytoplankton species. The rationale behind this expected inverse correlation is that at high growth rates RUBISCO becomes transport limited for $\mathrm{CO}_{2}$. This would result in undersaturation of RUBISCO and therefore a lower fractionation, as well as in a shift from $\mathrm{CO}_{2}$ to $\mathrm{HCO}_{3}^{-}$as the most important $\mathrm{C}$-source. Both will lead to increasing $\delta^{13} \mathrm{C}$ values. 


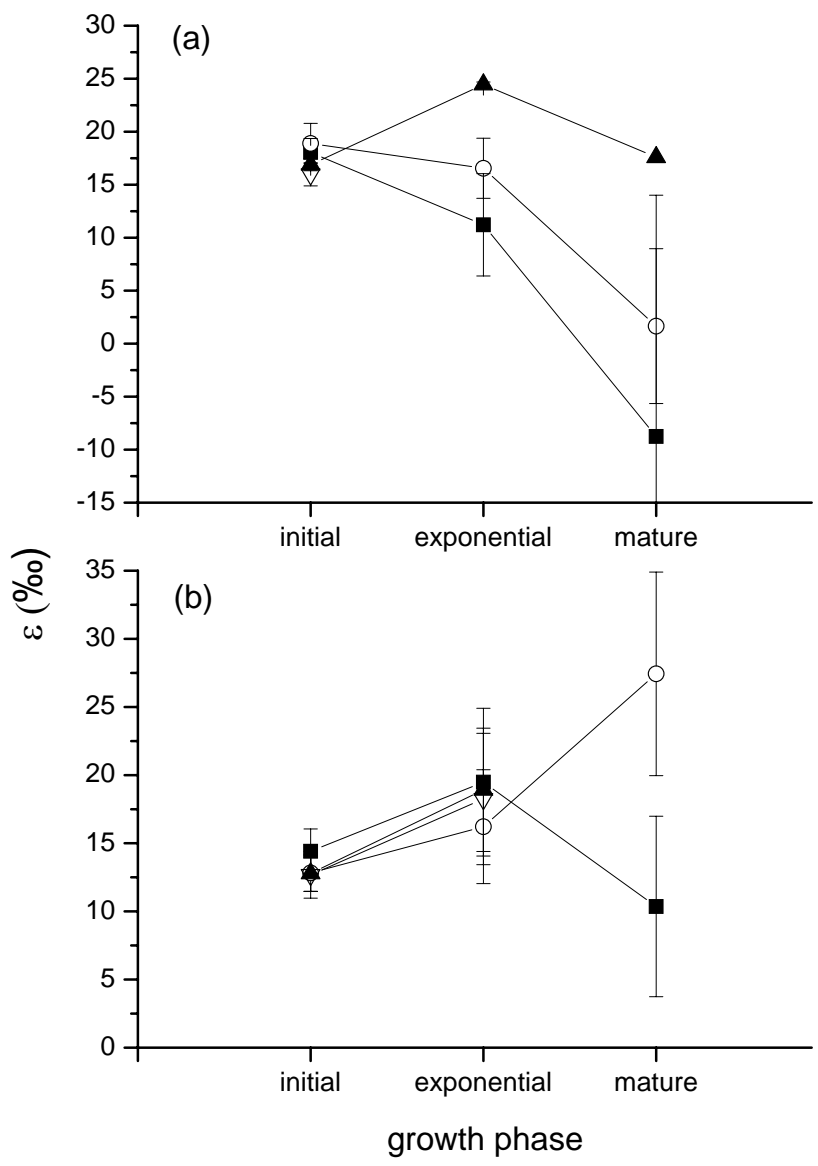

Fig. 4. Average fractionation $(\varepsilon)$ per irradiance during the three growth phases throughout the development of phototrophic biofilms. Biofilms were grown at incident photon fluxes of 120 (closed squares), 60 (open circles), 30 (closed triangles) and 15 (open triangles). The average values and error bars were calculated over successively 2 (freshwater, (a)) and 4 (marine, (b)) separate runs.

It can be assumed that irradiance determines growth during the initial stage, and that no other substrate than light is limiting at this stage. A non-linear relationship between the relative growth rate at $50 \%$ absorbance and irradiance was found (Fig. 1 and Table 1); logistic growth models describe that growth rates are highest during the initial phase. During this phase, the $\delta^{13} \mathrm{C}$ values were lowest. As soon as the availability of any substrate becomes limiting for growth, the net biofilm growth rate will decrease during further development. After this onset of limitation, we found increasing $\delta^{13} \mathrm{C}$ values and a decrease in fractionation in the freshwater biofilms indicating that the diffusive transport of $\mathrm{CO}_{2(\mathrm{aq})}$ became limiting in the biofilm during the later developmental stages.

In free-living phytoplankton, population-based results may closely reflect the average of individual cells, but in our biofilm communities we could only measure the depth
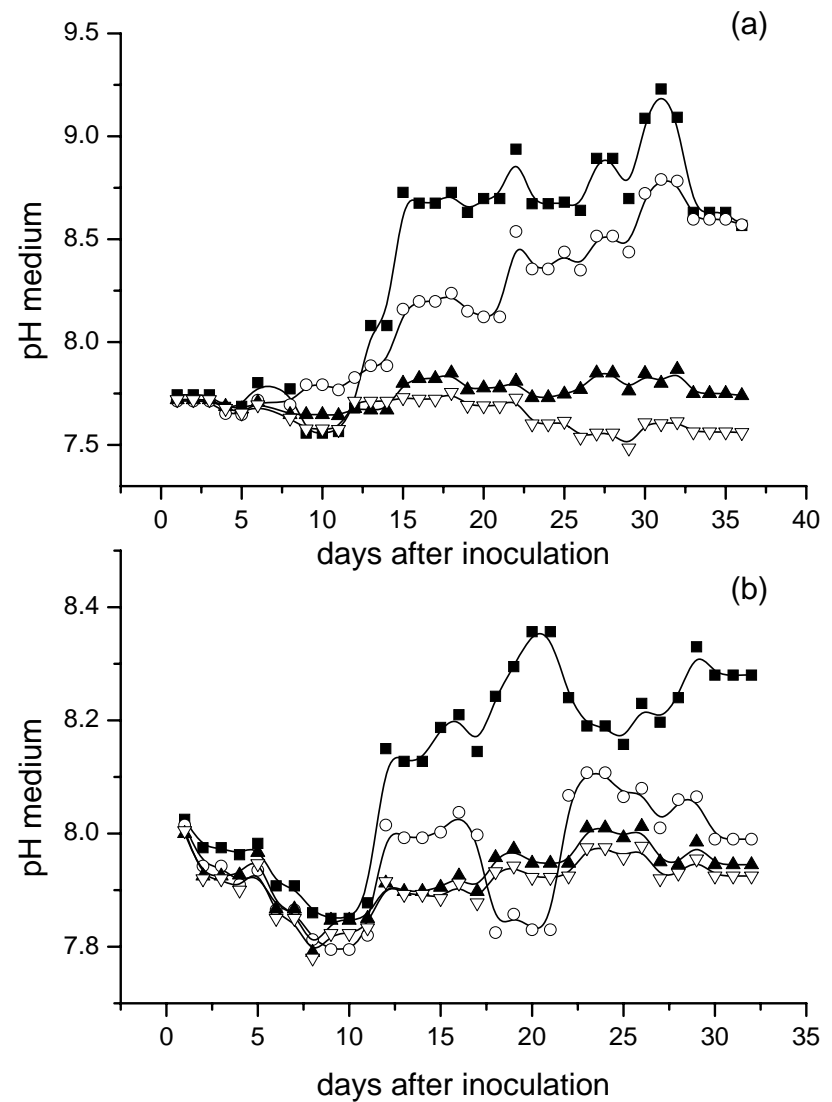

Fig. 5. Averaged $\mathrm{pH}$ of the overlaying growth medium $(\mathrm{n}=5)$ during the development of phototrophic biofilms grown at different irradiances and media ((a) freshwater medium, (b) marine medium). The media was refreshed twice a week, and the $\mathrm{pH}$ was assumed to be stable after half a day of incubation. Standard deviations are not given in the graph for visual clarity. The highest standard deviations were found in the $120 \mu \mathrm{mol}$ photons $\mathrm{m}^{-2} \mathrm{~s}^{-1}$ treatment. The average standard deviations at that irradiance were 0.55 and 0.19 for respectively the freshwater and marine runs. The maximum standard deviations of these runs were respectively 0.95 and 0.35 . The different incubation irradiances were 15 (open triangles), 30 (closed triangles), 60 (open circles) and $120 \mu$ mol photons $\mathrm{m}^{-2} \mathrm{~s}^{-1}$ (closed squares).

integrated value. Our model showed that the different Csources are not homogenously distributed with depth and that the depth integrated net-C fixation becomes increasingly $\mathrm{CO}_{2(\mathrm{aq})}$ limited with biofilm thickness, especially since heterotrophic biomass was lower in the freshwater biofilms. Low heterotrophic biomass cannot provide intensive carbon recycling of photosynthetic products during the light period.

Variations of $\delta^{13} \mathrm{C}$ values in biofilms may be due to changes in the $\mathrm{C}$-source rather than being solely the result of limited $\mathrm{CO}_{2}$ (aq) availability. We found a fractionation of $\sim 13-17 \%$ o for initial biofilm growth, and the modeled $\mathrm{C}$-concentrations and volumetric $\mathrm{C}$-fixation rates were relatively high, both indicating that $\mathrm{CO}_{2(\mathrm{aq})}$ was not limiting 

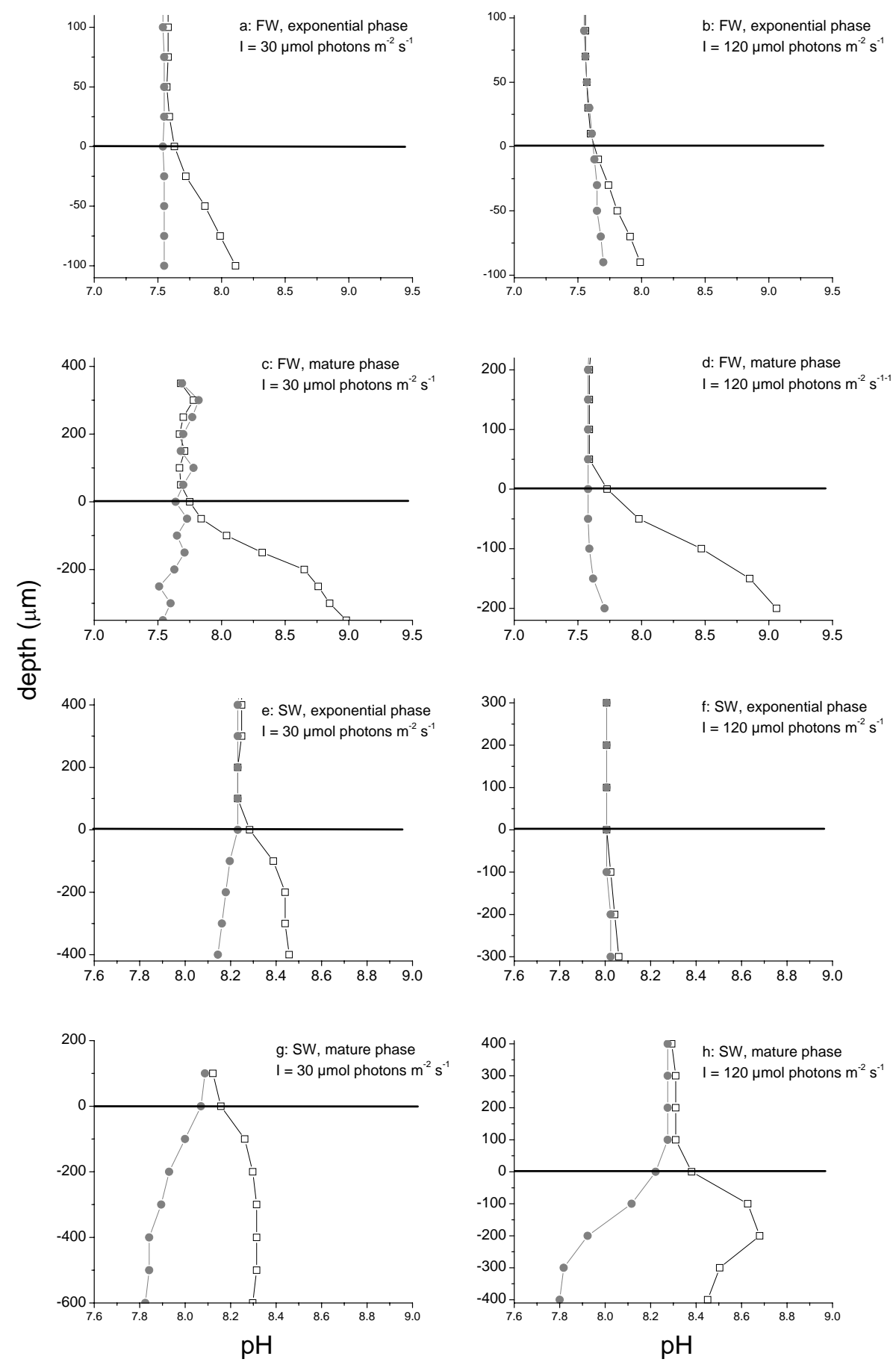

Fig. 6. $\mathrm{pH}$ micro profiles measured in biofilms of the exponential (a, b, e and f) and mature phase (c, d, g and h) in a freshwater (FW) at $30^{\circ} \mathrm{C}(\mathrm{a}-\mathrm{d})$ and a marine (SW) biofilm at $25^{\circ} \mathrm{C}(\mathrm{E}-\mathrm{H})$ at $2 \mathrm{~m} / \mathrm{s}$ flow. The biofilms have been grown at two irradiances: 30 (d, c, e and g) and $120 \mu \mathrm{mol}$ photons $\mathrm{m}^{-2} \mathrm{~s}^{-1}$ (b, d, f and h). Closed circles represent $\mathrm{pH}$ profiles measured in the dark, open squares represent $\mathrm{pH}$ profiles measured in the light. We only show profiles from one freshwater run and one marine run, which are representative for the other runs.

at that stage of biofilm formation (Fig. 7). During further thickening of the biofilm, model calculations showed that the depth integrated areal C-fixation rate increased, despite decreasing biofilm growth rates and a decrease in the aver- age volumetric $\mathrm{C}$-consumption rate. This resulted in a shift from $\mathrm{CO}_{2}$ towards $\mathrm{HCO}_{3}^{-}$as the most important $\mathrm{C}$-source for photosynthesis. This shift explains the progression towards less negative $\delta^{13} \mathrm{C}$ values observed in thick freshwater 

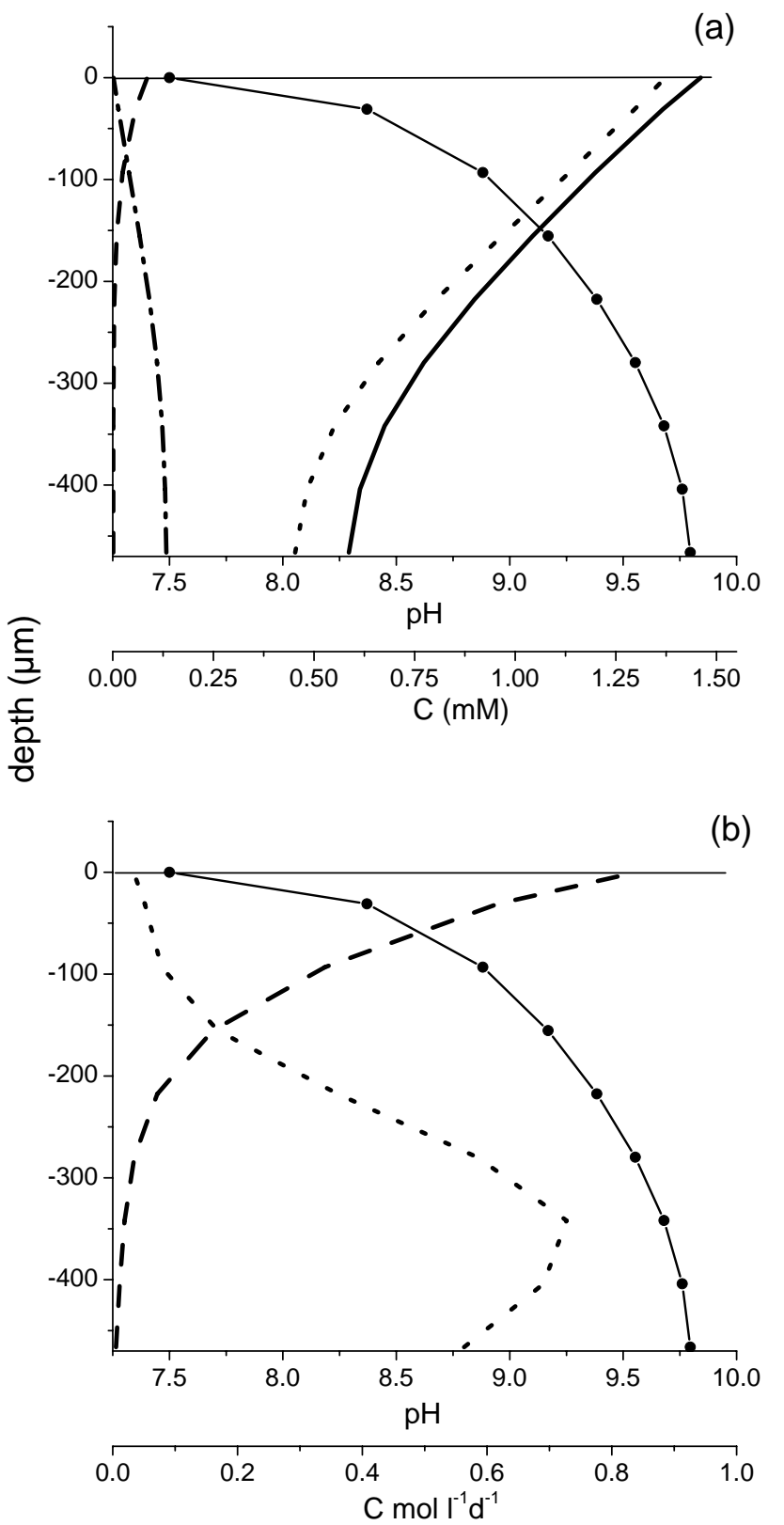

Fig. 7. (a) Modeled distribution of the C-species: $\mathrm{CO}_{2}$ (dashed line), $\mathrm{HCO}_{3}^{-}$(dotted line), $\mathrm{CO}_{3}$ (dash dotted line) and total inorganic $\mathrm{C}$ (solid line) over depth at $120 \mu \mathrm{mol}$ photons $\mathrm{m}^{-2} \mathrm{~s}^{-1}$ in a biofilm of $\sim 470 \mu \mathrm{m}$ thick. The $\mathrm{pH}$ is also expressed (closed circles). (b) Modeled carbon consumption rate with depth in a biofilm of $\sim 470 \mu \mathrm{m}$ thickness, at an irradiance of $120 \mu \mathrm{mol}$ photons $\mathrm{m}^{-2} \mathrm{~s}^{-1}$. Total inorganic carbon consumption is separated in a consumption rate of $\mathrm{CO}_{2}$ (aq) (dashed line) and $\mathrm{HCO}_{3}$ (dotted line). The water-biofilm surface at a depth of $0 \mu \mathrm{m}$ is indicated with a line.

biofilms. In addition, the model showed that the top layer $(<70 \mu \mathrm{m})$ was not limited by $\mathrm{CO}_{2(\mathrm{aq})}$ at an irradiance of $120 \mu \mathrm{mol}$ photons $\mathrm{m}^{-2} \mathrm{~s}^{-1}$ in a $500 \mu \mathrm{m}$ thick biofilm.

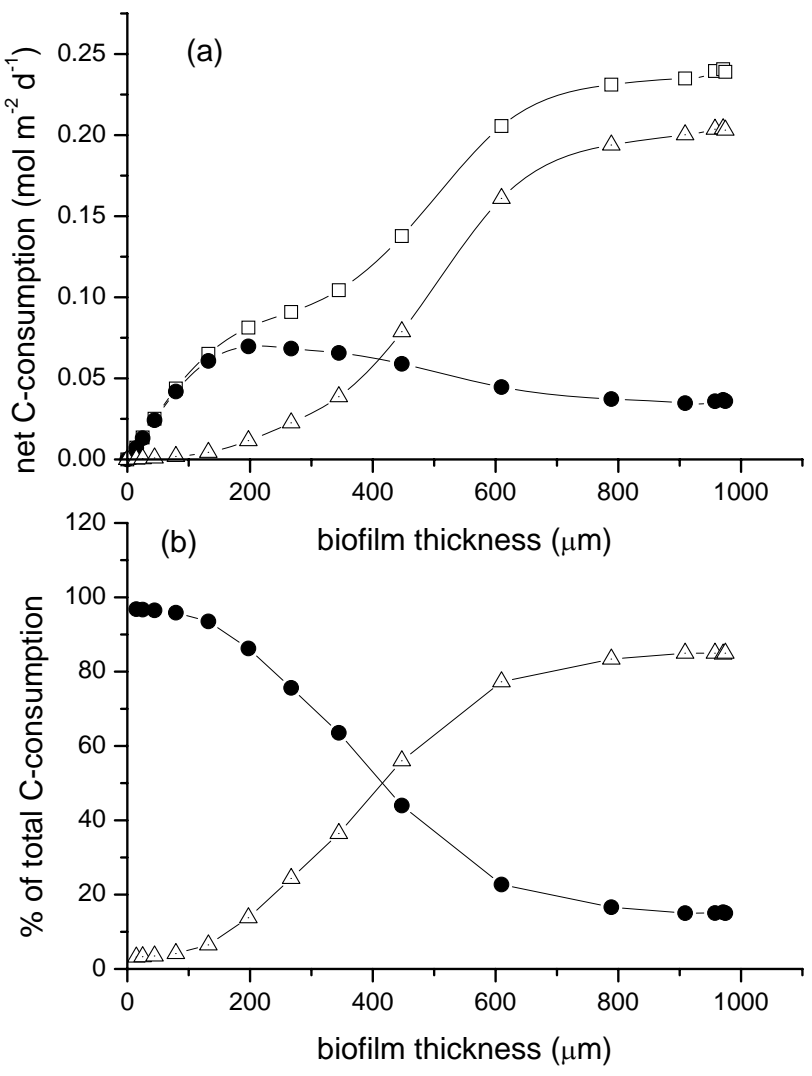

Fig. 8. Relationship between depth integrated C-consumption with the biomass development (biofilm thickness) based on a mechanistic model describing phototrophic biofilm growth (a) net-total inorganic $\mathrm{C}$ consumption (squares), $\mathrm{CO}_{2}$ consumption (circles) and $\mathrm{HCO}_{3}^{-}$consumption (triangles). The lower graph (b) indicates the shift in contribution from $\mathrm{CO}_{2}$ (closed circles) to $\mathrm{HCO}_{3}^{-}$(open triangles) to the total $\mathrm{C}$-consumption.

We also found that the difference in $\delta^{13} \mathrm{C}$ between the initial and stationary biofilm growth phase became larger at higher irradiances (Fig. 2). The opposite trend was found for fractionation at the different irradiances (less fractionation at higher irradiances, Fig. 4). Biofilm thickness was approximately similar (light absorption determined at the moment of sampling) for all sampled irradiances at each given sampling event. Therefore we conclude that for stationary-phase biofilms (i.e. no net growth) a relationship can be expected between depth integrated photosynthesis rate and $\delta^{13} \mathrm{C}$ fractionation.

Our data showed no correlation between the $\delta^{13} \mathrm{C}$ value and flow rate, although relationships between fractionation and mass transport or flow velocity are well described for phototrophic biofilms (France, 1995a; Larned et al., 2004; France, 1995b). However, these studies may have different flow regimes. Our system was developed to have as little turbulence as possible (Zippel et al., 2007), which was different from the system described by France (1995a) and Larned 
et al. (2004). Turbulence might affect biofilm development differently. Furthermore, the measured $\mathrm{pH}$ profiles indicated that the diffusive boundary layers were very thin, $50-150 \mu \mathrm{m}$ and $50-100 \mu \mathrm{m}$ for 0.5 and $2 \mathrm{~m} / \mathrm{s}$ flow respectively. This difference may not be enough to result in clear differences in $\delta^{13} \mathrm{C}$ values for both flow rates.

Another reason for the absence of the relationship with flow velocity may be that in the initial, or exponential growth phase of biofilms, mass transfer limitation is not an issue. Differences in diffusive boundary layer thickness, as a result of higher flow rates or turbulence levels during these early phases will not affect fractionation efficiencies for ${ }^{13} \mathrm{CO}_{2}$ by RUBISCO since $\mathrm{CO}_{2(\mathrm{aq})}$ availability is not a limiting factor for fractionation. From the same line of reasoning as was used for the growth rate (see above), it can be argued that a correlation between flow rate or turbulence and fractionation will only be found under diffusion limited conditions, i.e. late exponential and mature biofilms. So it may be that the correlation found in literature is caused by sampling preferences for mature biofilms. Developmental stages have not been taken into account in these studies. In natural systems it will be difficult to distinguish and sample from the different stages of the biofilm development, since heterogeneity in developmental stages are present on a small spatial scale, due to sloughing, grazing, etc (Biggs, 1996; Havens et al., 1996).

Initial $\delta^{13} \mathrm{C}$ values were less negative in the marine biofilms, while their relative growth rates did not differ from the freshwater biofilms. The difference in $\delta^{13} \mathrm{C}$ values can be partially explained by the $\delta^{13} \mathrm{DIC}$, which was $4-5 \%$ o less negative than in the freshwater medium, but part of the difference must be due to differences in fractionation during the initial phase. Lower fractionation can result from the lower $\mathrm{CO}_{2(\mathrm{aq})}$ concentration in the marine medium. However, neither the initial $\delta^{13}$ DIC, nor the lower $\mathrm{CO}_{2(\text { aq) }}$ explain the decrease in $\delta^{13} \mathrm{C}$ values with the thickening of the biofilms. It was calculated that the initial $\mathrm{CO}_{2(\mathrm{aq})}$ concentration in the marine medium was approximately 3-4 times lower than the freshwater medium despite the higher DIC concentrations. Therefore, it seems likely that the marine biofilms were more limited in $\mathrm{CO}_{2(\mathrm{aq})}$ than the freshwater biofilms. However, the high DIC may select for species with a high affinity for bicarbonate uptake from the start, and thus led to a relative high uptake of bicarbonate in the initial phase. Therefore there may not such a big shift from $\mathrm{CO}_{2}$ to bicarbonate as the primary $\mathrm{C}$-source. A decrease in $\delta^{13} \mathrm{C}$ values may also be explained by the expected decrease in growth rate with the thickening of the biofilm, as has been shown for phytoplankton species (Fry and Wainright, 1991; Laws et al., 1995; Rau et al., 1996). A prerequisite for this mechanism would be that the decrease in growth rate is caused by another factor than carbon limitation. However, the same amounts of micro-nutrients have been added to both types of media.

In our experiments, one clear difference between the freshwater and the marine biofilms was that heterotrophic biomass was twice as high in the marine biofilms. Higher het- erotrophic biomass is assumed to result in a higher recycling of carbon within the biofilm and as a result increase the availability of $\mathrm{CO}_{2(\mathrm{aq})}$. A lowering of the $\mathrm{pH}$ with depth in the dark, indicative for a high respiratory activity, was indeed found in the marine biofilms. A decrease in $\mathrm{pH}$ with depth in the dark was almost absent in the freshwater biofilms and as a result we conclude that a much higher heterotrophic activity was present within the marine biofilms. This was also confirmed from oxygen micro profile measurements (data not shown). Carbon cycling within a biofilm may reduce the $\delta^{13} \mathrm{C}$ value. It has been shown that as soon as ecosystems shift from phototrophic to heterotrophic systems this will lower the $\delta^{13} \mathrm{C}$ values (Schindler et al., 1997; Bade et al., 2004). High respiration rates increase the level of heterotrophy of the biofilm and elevate the $\mathrm{CO}_{2}$ cycling and its availability for the phototrophic organisms. Moreover, respiration enriches mostly the ${ }^{12} \mathrm{CO}_{2}$ pool since its source (biomass) is lighter, relative to the DIC pool.

In conclusion, we found that the $\delta^{13} \mathrm{C}$ value depends on the development phase of the phototrophic biofilm, and fractionation seems to be controlled by the balance between C-demand (net depth-integrated photosynthesis rates) and mass transfer limitation controlled by the biofilm thickness in combination with the depth integrated photosynthesis rate rather than by the actual biofilm growth rate. The freshwater biofilm model shows that initially our freshwater biofilms were not limited by $\mathrm{CO}_{2(\mathrm{aq})}$ in the light. $\mathrm{CO}_{2(\mathrm{aq})}$ only becomes limiting with the thickening of the biofilm, which results in a increase in importance of $\mathrm{HCO}_{3}$ as inorganic carbon source for photosynthesis.

However, the direction in which the $\delta^{13} \mathrm{C}$ value develops during biomass accretion seems to depend on: the net depth-integrated $\mathrm{C}$-fixation rate, changes in the utilization of the different inorganic $\mathrm{C}$-sources and the recycling rate of $\mathrm{C}$ driven by heterotrophic activity. In the marine incubation, most likely a higher heterotrophic activity in the biofilm combined with a low $\mathrm{CO}_{2(\mathrm{aq})}$ in the medium resulted in the completely opposite trend in $\delta^{13} \mathrm{C}$ values, when compared to the freshwater incubations. We cannot conclude whether heterotrophic recycling is always more important in marine systems than in freshwater systems, but in our system it was. This difference was found despite different, independently grown inoculums have been used to seed biomass in the different runs. Since surface-associated microalgae and cyanobacteria are amongst the most successful and efficient primary producers in benthic aquatic environments, and are considered a main source of energy for higher trophic levels in natural systems, such trends in $\delta^{13} \mathrm{C}$ value with biofilm developmental stages need to be taken into account if $\delta^{13} \mathrm{C}$ values of biofilm are used for food web studies.

Acknowledgements. A. Glud is thanked for manufacturing the $\mathrm{pH}$ microelectrodes. P. v.d. Berg and S. Jensen are thanked for running the incubators and assistance with the data collection. This work was financed by the European Union, PHOBIA, EU contract QLRT-2001-01938, and the Danish Natural Science 
Research Council (RT and MK). This is publication nr. 4129 of NIOO-CEME.

Edited by: T. J. Battin

\section{References}

Bade, D. L., Carpenter, S. R., Cole, J. J., Hanson, P. C., and Hesslein, R. H.: Controls of delta C-13-DIC in lakes: Geochemistry, lake metabolism, and morphometry, Limnnol. Oceanogr., 49, 1160-1172, 2004.

Biggs, B. J. F.: Patterns in benthic algae of streams, in: Algal Ecology: Freshwater Benthic Ecosystems, edited by: Stevenson, R. J., Bothwell, M. L., and Lowe, R. L., San Diego, Academic Press, 31-56, 1996.

Boschker, H. T. S.: Linking microbial community structure and functioning: stable isotope (13C) labeling in combination with PLFA analysis, in: Molecular Microbial Ecology Manual II, edited by: Kowalchuk, G. A., de Bruijn, F. J., Head, I. M., Akkermans, A. D., and van Elsas, J. D., Dordrecht, The Netherlands, Kluwer Academic Publishers, 1673-1688, 2004.

Boschker, H. T. S., Kromkamp, J. C., and Middelburg, J. J.: Biomarker and carbon isotopic constraints on bacterial and algal community structure and functioning in a turbid, tidal estuary, Limnnol. Oceanogr., 50, 70-80, 2005.

Bott, T. L.: Algae in microscopic food webs, in: Algal Ecology: Freshwater Benthic Ecosystems, edited by: Stevenson, R. J., Bothwell, M. L., and Lowe, R. L., San Diego, Academic Press, 574-609, 1996.

Cassar, N., Laws, E. A., Bidigare, R. R., and Popp, B. N.: Bicarbonate uptake by Southern Ocean phytoplankton, Global Geochem. Cy., 18, 1-10, 2004.

Charlebois, P. M. and Lamberti, G. A.: Invading crayfish in a Michigan stream: Direct and indirect effects on periphyton and macroinvertebrates, J. N. Am. Benthol. Soc., 15, 551-563, 1996.

Congestri, R., Cox, E. J., Cavacini, P., and Albertano, P.: Diatoms (Bacillariophyta) in phototrophic biofilms colonising an italian wastewater treatment plant, Diatom Res., 20, 241-255, 2005.

Decho, A. W.: Microbial biofilms in intertidal systems: an overview, Cont. Shelf Res., 20, 1257-1273, 2000.

delGiorgio, P. A. and France, R. L.: Ecosystem-specific patterns in the relationship between zooplankton and POM or microplankton delta C-13, Limnol. Oceanogr., 41, 359-365, 1996.

Dijkman, N. A. and Kromkamp, J. C.: Phospholipid-derived fatty acids as chemotaxonomic markers for phytoplankton: application for inferring phytoplankton composition, Mar. Ecol. -Prog. Ser., 324, 113-125, 2006.

Eilers, P. H. C. and Peeters, J. C. H.: A model for the relationship between light-intensity and the rate of photosynthesis in phytoplankton, Ecolog. Model., 42, 199-215, 1988.

France, R. L.: Differentiation between littoral and pelagic food webs in lakes using stable carbon isotopes, Limnol. Oceanogr., 40, 1310-1313, 1995a.

France, R. L.: C-13 enrichment in benthic compared to planktonic algae - foodweb implications, Mar. Ecol.-Prog. Ser., 124, 307312, $1995 b$.

France, R. L.: Stable isotopic survey of the role of macrophytes in the carbon flow of aquatic foodwebs, Vegetatio, 124, 67-72, 1996.
Freeman, K. H. and Hayes, J. M.: Fractionation of carbon isotopes by phytoplankton and estimates of ancient $\mathrm{CO}_{2}$ levels, Global Biogeochem. Cy., 6, 185-198, 1992.

Fry, B. and Wainright, S. C.: Diatom sources of C-13-rich carbon in marine food webs, Mar. Ecol.-Prog. Ser., 76, 149-157, 1991.

Glud, R. N., Ramsing, N. B., and Revsbech, N. P.: Photosynthesis and photosynthesis-coupled respiration in natural biofilms quantified with oxygen microsensors, J. Phycol., 28, 51-60, 1992.

Goericke, R., Montoya, J. P., and Fry, B.: Physiology of isotopic fractionation in algae and cyanobacteria, in: Stable isotopes in ecology and environmental science, edited by: Lajtha, K. and Michner, R. H., Oxford, Blackwell Scientific Publications, 187221, 1994.

Havens, K. E., East, T. L., Meeker, R. H., Davis, W. P., and Steinman, A. D.: Phytoplankton and periphyton responses to in situ experimental nutrient enrichment in a shallow subtropical lake, J. Plankton Res., 18, 551-566, 1996.

Hayes, J. M.: Factors controlling C-13 contents of sedimentary organic-compounds - Principles and evidence, Mar. Geol., 113, 111-125, 1993.

Johnston, N. T., MacIsaac, E. A., Tschaplinski, P. J., and Hall, K. J.: Effects of the abundance of spawning sockeye salmon (Oncorhynchus nerka) on nutrients and algal biomass in forested streams, Can. J. Fish. Aquat. Sci., 61, 384-403, 2004.

Larned, S. T., Nikora, V. I., and Biggs, B. J. F.: Mass-transferlimited nitrogen and phosphorus uptake by stream periphyton: A conceptual model and experimental evidence, Limnnol. Oceanogr., 49, 1992-2000, 2004.

Laws, E. A., Popp, B. N., Bidigare, R. R., Kennicutt, M. C., and Macko, S. A.: Dependence of phytoplankton carbon isotopic composition on growth-rate and $\left[\mathrm{CO}_{2}\right]_{(\mathrm{Aq})}$ - theoretical considerations and experimental results, Geochim. Cosmochim. Ac., 59, 1131-1138, 1995.

Lewis, M. A., Weber, D. E., Goodman, L. R., Stanley, R. S., Craven, W. G., Patrick, J. M., Quarles, R. L., Roush, T. H., and Macauley, J. M.: Periphyton and sediment bioassessment in north Florida Bay, Environ. Monit. Assess., 65, 503-522, 2000.

March, J. G. and Pringle, C. M.: Food web structure and basal resource utilization along a tropical island stream continuum, Puerto Rico, Biotropica, 35, 84-93, 2003.

Rau, G. H., Riebesell, U., and Wolf-Gladrow, D.: A model of photosynthetic $\mathrm{C}-13$ fractionation by marine phytoplankton based on diffusive molecular $\mathrm{CO}_{2}$ uptake, Mar. Ecol-Pog. Ser., 133, 275285, 1996.

Roeske, C. and O'Leary, M.: Carbon isotope effect on carboxylation of ribulase biphosphate catalyzed by ribulase biphosphate carboxylase from Rhodospirillum rubrum, Biochemistry, 24, 1603-1607, 1985.

Rost, B., Zondervan, I., and Riebesell, U.: Light-dependent carbon isotope fractionation in the coccolithophorid Emiliania huxleyi, Limnol. Oceanogr., 47, 120-128, 2002.

Schindler, D. E., Carpenter, S. R., Cole, J. J., Kitchell, J. F., and Pace, M. L.: Influence of food web structure on carbon exchange between lakes and the atmosphere, Science, 277, 248-251,1997.

Sidorkewicj, N. S., Lopez Cazorla, A. C., Fernandez, O. A., Mockel, G. C., and Burgos, M. A.: Effects of Cyprinus carpio on Potamogeton pectinatus in experimental culture: the incidence of the periphyton, Hydrobiologia, 415, 13-19, 1999.

Stumm, W. and Morgan, J. J.: Aquatic chemistry: Chemical equi- 
libria and rates in natural waters, New York, Wiley-Interscience, 1995.

Swansburg, E. O., Fairchild, W. L., Fryer, B. J., and Ciborowski, J. J. H.: Mouthpart deformities and community composition of chironomidae (diptera) larvae downstream of metal mines in New Brunswick, Canada. Environ. Toxicol. Chem., 21, 2675-2684, 2002.

Tortell, P. D. and Morel, F. M. M.: Sources of inorganic carbon for phytoplankton in the eastern Subtropical and Equatorial Pacific Ocean, Limnnol. Oceanogr., 47, 1012-1022, 2002.

Trudeau, V. and Rasmussen, J. B.: The effect of water velocity on stable carbon and nitrogen isotope signatures of periphyton, Limnol. Oceanogr., 48, 2194-2199, 2003.
Werne, J. P. and Hollander, D. J.:Balancing supply and demand: controls on carbon isotope fractionation in the Cariaco Basin (Venezuela) Younger Dryas to present, Mar. Chem., 92, 275293, 2004.

Wolf, G., Picioreanu, C., and van Loosdrecht, M. C. M.: Kinetic modeling of phototrophic biofilms: The PHOBIA model, Biotechnol. Bioeng., 97, 1064-1079, 2007.

Zippel, B. and Neu, T. R.: Growth and structure of phototrophic biofilms under controlled light conditions, Water Sci. Technol., 52, 203-209, 2005.

Zippel, B., Rijstenbil J., and Neu T. R.: A flow-lane incubator for studying freshwater and marine phototrophic biofilms, J. Microbiol. Meth., 70, 336-345, doi:10.1016/j.mimet.2007.05.013, 2007. 